\title{
INDIVIDUAÇÃO E LAÇOS SOCIAIS EM PERIFERIAS URBANAS: REFLEXÕES DESDE A PRODUÇÃO DE NARRATIVAS
}

\section{INDIVIDUATION AND SOCIAL BONDS IN URBAN PERIPHERIES: REFLECTION FROM PRODUCTION OF NARRATIVES}

\author{
Leandro R. Pinheiro' \\ 1 Universidade Federal do Rio Grande do Sul, Brasil, e-mail: leandropinheiro75@gmail.com
}

\author{
ART ICLE INFO \\ Article history: \\ Received 2020-01-15 \\ Accepted 2020-04-10 \\ Available online 2020-04-10
}

Palavras-chave: Individuação. Laços sociais. Narrativas. Risco. Periferias urbanas.

Keywords: Individuation. Social bonds. Narratives. Risk. Urban Peripheries.

RESUMO. O artigo traz problematizações articuladas a algumas mudanças sociais atinentes à 'modernidade tardia', propondo, contudo, a abordagem de sua difração em localidades de periferia urbana. Neste sentido, tomando informações produzidas em incursões a contextos socialmente vulnerabilizados na cidade de Porto Alegre/RS, entre 2010 e 2017, o texto procura discutir os processos de individuação produzidos por seus moradores. As proposições de Danilo Martuccelli foram os principais referentes em nossas análises, com destaque à noção de 'prova-social', sendo que as atividades em campo foram desenvolvidas com base sobretudo na produção de "entrevistas narrativas". Procede-se à análise dos depoimentos desde a apropriação de elementos da pesquisa biográfica, tomando complementarmente contribuições da análise estrutural de narrativas. A partir daí, aventa-se a configuração de uma individuação agêntica, conforme já assinalava o autor supracitado, mas que, em período recente, tende a se associar à vivência social do "risco". Assim, tendo-se em conta principalmente a flexibilização das relações laborais e a intensificação de conflitos armados nos territórios, a produção de laços sociais se converte em arena patente de desafios com vistas à manutenção de vínculos de reciprocidade e convivência fiável desde o trabalho dos próprios indivíduos.

\begin{abstract}
This study proposes an articulated discussion vis-à-vis some social changes regarding 'late modernity,' proposing, however, the consideration of its diffraction in urban peripheries. Thus, upon considering the data collected in the incursions to socially vulnerable areas in Porto Alegre, Brazil, between 2010 and 2017, this paper proposes a discussion about individualization processes engendered by the denizens of these places. Danilo Martucelli's propositions constitute the main theoretical references for our analysis, especially regarding the notion of 'social trial', and the field activities were developed on the basis of "narrative interviews" mostly. We analyze the statements in accordance with elements of biographical research, taking complementary contributions from the structural analysis of narratives. This fostered considerations about the constitution an agentive individualization - as pointed out by the aforementioned author -, which, recently, may be associated to the social experiencing of "risk." Therefore, upon especially considering the flexibilization of labor relations and the intensification of armed conflicts in the territories, the establishment of social bonds becomes an arena of patent challenges with the aim of maintaining the reciprocal bonds and the trustworthy coexistence for the individuals' engagements.
\end{abstract}




\section{Introdução}

O debate sobre as formas de produção social dos indivíduos e/ou os modos de configuração de perspectivas e práticas individualistas junto a processos de urbanização moderna não são novidade no campo das ciências sociais. Gilberto Velho (2000) trazia pertinente destaque neste sentido, assinalando as contribuições de Georg Simmel, Louis Dumont e Max Weber, entre outros, para provocar-nos a refletir sobre o anonimato relativo construído nos espaços urbanos ocidentais desde a multi-referencialidade e a circulação que estes engendram aos percursos individualizados. Também Velho (2000) situava as hierarquias sociais e a iniquidade do capitalismo que constitui nossa história, dispondo, particularmente em favelas e periferias urbanas, situações de violência extrema e o tensionamento de laços locais pela intrusão de lógicas do mercado de tráfico de drogas e armas, que, não raro, guarda certa homologia com os modos de ação policialescos estatais.

De longa data, ademais, as análises acadêmicas vêm apresentando versões das condições de vida e do cotidiano de comunidades socialmente vulnerabilizadas. Têm traçado modos de convivialidade, formas de identificação e práticas (ZALUAR, 1994), bem como as repercussões das políticas sociais na conformação das sociabilidades e da relação com a esfera pública (FELTRAN, 2014; GEORGES, 2016). Intentamos, aqui, estabelecer uma interlocução com tais contribuições, com argumentação dirigida, entretanto, aos processos de individuação em periferias urbanas e, conforme tem indicado as incursões em campo, assinalando o trabalho dos indivíduos na produção e manutenção de laços sociais.

Neste artigo, dirigimos nossa atenção para os itinerários biográficos, considerando-os uma forma pertinente para compreensão das experiências produzidas nas relações sociais contemporâneas. Partimos das proposições de Danilo Martuccelli (2007; 2010; 2010b) neste sentido, tomando especialmente a noção heurística de "prova-social" como inspiração para análise das narrativas que produzimos em campo. Almejamos, com isso, uma aproximação dedicada aos agenciamentos operados por moradores e ativistas daqueles loci no enfrentamento de desafios estruturais, de modo a esboçar dinâmicas de individuação contextualizadas.

Assim, o texto que segue traz uma breve apresentação dos referenciais centrais em nosso trabalho e da forma como procedemos a análise das narrativas que produzimos em localidades de periferia de Porto Alegre, entre os anos de 2010 e 2017. Em seguida, dedicase à interpretação do que nos fora narrado em campo. 


\section{Referentes do percurso}

Para Martuccelli (2007, 2010b), a produção social de indivíduos na contemporaneidade passa por uma intensa singularização, de modo que as dinâmicas de socialização merecem problematizações que desbordem categorias macro sociológicas usuais (classe, gênero, etnia, idade etc.), ainda que sem perder de vista sua importância.

Nesse sentido, sugere que consideremos o conjunto de "provas estruturais" a que, em geral, os indivíduos estão submetidos. Define a estas como "desafios históricos, socialmente produzidos, culturalmente representados, desigualmente distribuídos, que os indivíduos estão obrigados a enfrentar no seio de um processo estrutural de individuação" (ARAUJO; MARTUCCELLI, 2010, p. 83). Ao estabelecer tal vetor metodológico, Martuccelli (2007) pretende se acercar da experiência que os indivíduos constroem em suas interações sociais, de modo que possa ampliar a compreensão dos movimentos que os sujeitos fazem. Nessa perspectiva, então, a interpretação se orienta ao que provoca o "trabalho dos indivíduos" em suas existências.

Segundo o autor, as "provas-sociais" teriam quatro características principais. Primeiramente, apresentam uma dimensão narrativa desde a qual os sujeitos entendem seus percursos e dispõem desafios constituintes, como herdeiros de uma aventura propriamente moderna. Segundo, trazem referências às capacidades dos indivíduos para fazer frente às provas, em geral, aventadas como tarefas pessoais. Remetem-nos também a processos de avaliação social, a partir dos quais cabe observar os diferenciais de resposta e os recursos efetivamente mobilizados para tanto. E, por fim, articulam-se a um conjunto de desafios estruturais compulsórios e significativos no marco de determinada sociedade, sejam eles institucionalizados ou relativos à produção de laços sociais, e variáveis conforme período histórico (MARTUCCELLI, 2007).

Tarefa complementar, então, consubstancia-se na análise das bases que sustentam o cotidiano dos indivíduos para chegarmos ao que o autor denomina "suportes". Martuccelli (2007 e 2008) procura designar o conjunto de recursos e apoios que sustentam as experiências dos atores, não na forma de um inventário das condições e recursos disponíveis a eles conforme a posição social, mas como uma ecologia existencial dos elementos apropriados no processo de individuação que se inscrevem na trama de interdependências efetivas das histórias individuais.

Por esse caminho, inclusive, Martuccelli (2010) ensaia argumentos acerca da existência de um "hiper-ator" nas sociedades latino americanas. Segundo ele, o individualismo latino-americano não se erigiria necessariamente na ficção de um contrato social entre indivíduos preconcebidos, produzido por organizações e programas institucionais, como na Europa; constituir-se-ia desde práticas e habilidades de pessoas que, para se integrarem à sociedade, precisam, antes de tudo, atuar e garantir existência e reconhecimento. 
Condição essa que se explicaria, em parte, pela forma como o poder se instaura no continente. Algo que se não estabeleceria tal como no "Norte"; algo que se indica, mas não se efetiva totalmente, como a lei que não se cumpre sempre, que varia nas circunstâncias, com uso da violência se necessário. De tal forma que esse indivíduo que precisa atuar (frente ao incerto do não funcional das instituições, ou do arbitrário do poder), precisa do outropróximo para sobreviver, já que os aparatos impessoais modernos não representam suporte estável. Então, a manutenção dos laços sociais torna-se fundamental à organização da experiência, sendo que, historicamente, redes bastante delimitadas suportariam as trajetórias dos sujeitos em seus cotidianos (e não só os programas institucionais).

\subsection{A produção e a análise de narrativas}

Buscamos discutir os processos de individuação de nossos interlocutores desde as provas estruturais do 'trabalho' e do 'território', notadamente significativas aos itinerários de vida narrados. Nos limites deste texto, não poderemos tratar de cada prova especificamente, mas propomos sua abordagem por meio da análise e contraste das configurações narrativas.

Em campo, realizamos entrevistas narrativas principalmente (JOVCHELOVITCH, 2002), porém, diferenciando-nos dos propósitos da pesquisa biográfica (DELORYMOMBERGER, 2012; SCHÜTZE, 2010). Não nos detínhamos a processos de produção do curso da vida ou ao estudo das especificidades das elaborações biográficas, secundando as interpelações dos constrangimentos sociais. Como se pode depreender do referencial supracitado, os diferentes percursos narrados que consideramos visavam a compreensão de uma experiência coletiva comum. Desta forma, a terceira parte da entrevista narrativa, em nosso caso, orientava-se a questões temáticas que apoiassem o aprofundamento das narrações no que concerne ao trabalho dos indivíduos no enfrentamento de provas sociais.

A análise das narrativas que empreendemos combinava dois vetores de interpretação. Procuramos selecionar os trechos estritamente narrativos dos depoimentos, conformando etapas de vida, situações culminantes, entrelaçamentos de eventos, como sugere Schütze (2010). No entanto, nossa sistematização dedicava-se à descrição e contraste entre recursos sociais acessados/mobilizados pelos indivíduos e, logo, dirigia-se a uma seleção temática conforme categorias empíricas indutivamente evocadas, e que nos ajudassem a elencar os movimentos operados pelo conjunto dos sujeitos (astúcias, redes de ação, etc.). Até este ponto, buscamos especialmente elementos indexáveis, para usar termo empregado por Jovchelovitch (2002).

O outro vetor de interpretação agrega, de maneira complementar, a condição performática da narrativa. Cabe considerar, nessa perspectiva, que a narrativa é uma das formas de configurar a experiência, mas desde as aporias da vivência do tempo, isto é, a partir de um olhar retrospectivo e segundo incidem as projeções no delineamento das memórias 
(ROCHA; ECKERT, 1999). Lembrando as provocações de Certeau (2011), a narração é uma "arte" e tem sua temporalidade própria, seja porque se erige como olhar retrospectivoprojetivo, seja porque condensa agenciamentos próprios no arranjo de tempos e ações. Significa dizer que, para os propósitos que delineamos aqui, entendemos tarefa profícua tomar também as narrativas desde a inteligibilidade que seus enredos indiciam.

Certeau (2011) provoca-nos a pensar, pois, sobre as homologias entre as "astúcias da prática" e as "astúcias da narrativa". Diz ele que o conto popular, por exemplo, é a teoria da prática contada, "é um saber-dizer ajustado ao seu objeto" (p. 141), que não relata, narra. As "artes do fazer" e do "dizer" se associam no modo astucioso de sua produção: o suspender temporário dos obstáculos de uma relação assimétrica para sair adiante, de um lado; a configuração da proeza desde o "tato" para produzir não o ato, mas os efeitos expectantes aos interlocutores. A narrativa não descreve, agencia os fatos e, assim, indicia também o sistema de interpretação que a constitui: "sombras da prática cotidiana que consiste em aproveitar a ocasião e fazer da memória o meio de transformar os lugares" (p. 150).

Por conseguinte, tomamos de empréstimo as proposições de Barthes (2011) para uma análise estrutural de narrativas. Assim, identificamos elementos a seccionar para leitura dos relatos, discriminando personagens, ações e funções e, para efeito desta escrita, distinguindo possíveis índices utilizados nas artes de narrar. Como não estamos, porém, trabalhando com narrativas literárias, procuramos dar atenção às peculiaridades dos enredos em entrevistas. Embora possamos aventar a hipótese de uma relação de contiguidade e complementaridade entre as narrativas ficcionais e os enredos elaborados pelos sujeitos no organizar de suas vivências, entendemos necessário assinalar que estes se singularizam de maneira bastante explícita. Seguindo ainda as contribuições de Barthes (2011), aventamos que, contendo conotação e denotação, a proporção destas nos enredos elaborados em diálogos de pesquisa se distinguem, tendendo à segunda. Da mesma maneira, não se trata necessariamente de um narrar que postula uma mensagem ou provocação deliberada previamente. A intencionalidade tende a se apresentar de maneira implícita e sócio relacional, conforme o instante de interação, a intermitência e a intenção das perguntas.

A análise da estrutura da narrativa assume, assim, um caráter complementar às análises temáticas anteriores. Assumindo a hipótese da homologia entre artes de narrar e artes de fazer, a performance narrativa nos apoia a compreender as ênfases valorativas dadas pelos sujeitos na narrativização de suas individualidades.

Para que a complementaridade seja afirmada, no entanto, cabe ter em conta que, se as narrativas produzidas evocam temporalidade e relação com historicidade, elas se deram numa interação específica, de entrevista. Para atenuar os efeitos de tal recorte circunstancial, assim como o do caráter retrospectivo e configurador da narrativa biográfica, procuramos atuar na observação etnográfica (ROCHA; ECKERT, 2008) e na diversificação das modalidades e momentos de narração (com a realização de rodas de conversa, especialmente), de tal 
forma que as entrevistas fossem a culminância de um processo de diálogos e registros. Além disso, o contraste entre os itinerários também se prestou para identificar fatos e práticas recorrentes (ou divergentes) e distribuídas a grupos e localidades diversas, trazendo, de certa forma, elementos que nos remetessem às condições objetivas dos interlocutores.

\subsection{0 acervo}

As entrevistas que compõem o conjunto em análise se deram com indivíduos identificados com distintas atividades laborais, artísticas ou esportivas, entre os anos de 2010 e 2017. Totaliza hoje aproximadamente 160 registros e é composto de narrativas de pessoas entre 15 e 80 anos de idade, consultadas por atuarem em localidades socialmente vulnerabilizadas da cidade de Porto Alegre/RS. Cerca de 65\% destas, além de atuarem, residiam em tais lugares. No que tange à escolaridade, aproximadamente $45 \%$ dos sujeitos tinha ensino fundamental (incompleto ou completo) à época das entrevistas, ao passo que $18 \%$ declararam ter ensino médio (incompleto ou completo) e $37 \%$ ensino superior (completo ou incompleto) ${ }^{1}$. Se tomamos uma segmentação etária em grandes faixas, o contingente possui 36\% de indivíduos jovens (15 a 29 anos de idade), 48\% de adultos (30 a 59 anos) e $16 \%$ de idosos. Os registros contam com um número ligeiramente superior de consultas a mulheres (60\%), em boa medida por conta da interlocução com pessoas atuantes na área de educação e assistência social.

As localidades que, aqui, aludimos são os bairros Bom Jesus, Cruzeiro, Lomba do Pinheiro, Restinga e Rubem Berta, situados em diferentes regiões do município. Todos têm histórico de crescimento populacional expressivo nos anos 1960-70 por conta de fluxos migratórios provocados por ações governamentais, automação de atividades agrícolas e por disputas do mercado imobiliário (NUNES, 2006; MOURA, 1996). Considerando séries estatísticas publicadas pelo Observatório da Cidade de Porto Alegre (OBSERVAPOA, 2017), uma análise comparativa evidencia que estas localidades estavam entre as mais vulnerabilizadas econômica e culturalmente. Os índices de violência, especificamente, apresentam cenários com taxas de homicídio (particularmente de jovens negros) superiores à média municipal².

Mesmo que tenhamos o conjunto do acervo como base, adotaremos, ademais, o artifício narrativo de contrastes entre itinerários por uma coorte etária. Pretendemos distinguir mudanças vivenciadas nas últimas décadas e, desta forma, ensaiar uma leitura qualitativa e

\footnotetext{
${ }^{1}$ Cabe registrar que, se tomamos dados somente de pessoas residentes em localidades socialmente vulnerabilizadas, o percentual de pessoas com ensino superior cai drasticamente. Ademais, a maioria se situaria no primeiro quintil de renda.

${ }^{2}$ Convém esclarecer que, segundo o Atlas da Violência (CERQUEIRA et al, 2018), Porto Alegre seria a sétima capital mais violência do país (taxa de homicídios de 58\% no ano de 2016).
} 
situada no cotidiano de alterações macrossociais. Caminho esse que nos oportunizará refletir sobre nuances nas dinâmicas de individuação.

\section{Periferias: a narração dos itinerários e suas nuances}

Orientando-nos, então, aos percursos narrados por moradores de contextos de periferia, embora tenhamos nuances conforme o nível de empobrecimento, há elementos comuns a destacar na configuração dos relatos. Primeiramente, destacam-se sobremaneira as intermitências e mudanças de rumo lançadas por questões de subsistência e/ou precarização do entorno. O predomínio de fatos associados ao trabalho é patente, delineando a narrativa e evidenciando os recorrentes agenciamentos cotidianos.

[...] Aí nós fizemo assim, eu com meu irmão. Meu irmão ganhava também, tava no quartel aquela época né? Então nós fomo juntando dinheiro e aluguemo uma casa, compremo uma casa e busquemo a mãe [...] Então, como minha mãe se criô trabalhando, então ela: "sabe o que que eu vou fazê, eu vô começá a fazê comida pra vendê pra fora". E começô e ali nós se alevantemos [...] (Zelândia, aposentada $-\operatorname{dez} / 2012)^{3}$

As dinâmicas familiares tendem a se sobressair como suporte. Ao mesmo tempo que as relações com parentes eram o contexto da responsabilização por tarefas quando ainda eram crianças, estas conformam também redes de reciprocidade que, eventualmente, podem se estender aos vizinhos, sendo a salva-guarda quando da necessidade de recurso, acolhida e pouso para migrações inclusive. A qualidade de tais relações varia sobremaneira e pode interferir nas possibilidades de obtenção de trabalho ou na gestação de referências simbólicas que acompanhavam nossos interlocutores em seus itinerários.

Por vezes, outras redes compunham o quadro de suportes. Agremiações culturais e comunitárias entre os ativistas nos bairros poderiam garantir reconhecimento e ampliação das práticas de sociabilidade; a filiação a igrejas possibilitariam a integração de grupos de partilha moral, referências simbólicas e oportunidades de trabalho eventualmente. De todo modo, os suportes narrados tendem a evidenciar redes de reciprocidade familiares e de amizade/vizinhança, denotando certa informalidade e uma presença rarefeita, quando não diáfana, de aparatos institucionais e corporativos associados à produção de capital cultural e estabilização de vínculos empregatícios. Assim, entendemos nos aproximar das proposições de Souza (2009), acerca da formação da "ralé brasileira".

Então, a cronologia do percurso tende a se explicitar em sequências de atuações pessoais, em lutas cotidianas por garantir subsistência, algum conforto ou a manutenção das sociabilidades. Não raro (não há como não mencionar), tais lutas eram apresentadas em inter-

${ }^{3}$ Optamos por respeitar os modos de fala de nossos interlocutores nas transcrições. Cremos que realçam características das circunstâncias de vida dos contextos em foco. 
relação com a chancela de alguma forma de transcendência. Aqui, não se trata de vinculação a uma religião explicitamente; na maioria das vezes, expressava certa experiência popular do sagrado (SANCHIS, 2008), que compreende a existência cotidiana em articulação à ação de entidades extraterrenas, evocando-as em sentenças que interseccionam os fatos narrados, em menção à proteção devida ou à gratidão pelo recurso logrado.

Passemos, agora, à análise de alguns elementos da configuração narrativa, o que poderá complementar nossas inferências.

\subsection{Artes de dizer: narrativas e agenciamentos}

Como já mencionado antes, a narração em entrevistas tende a destacar o teor denotativo (BARTHES, 2011), de forma que a conotação, muitas vezes, situa-se não exatamente no manejo de índices ao longo da interlocução, mas pelo que se indicia na totalidade do ato vivenciado ou do próprio itinerário contado. Neste caso, era a fabulação de si que era aludida, em juízos professados ocasionalmente nas entrevistas, valorando o conjunto dos acontecimentos e feitos. Não raro, indicavam posições ambivalentes (por exemplo: sofrimento-graça; penúria-abundância; alienação-conhecimento) enlaçadas a menções de astúcia, determinação e superação.

No entanto, uma mirada a casos mais reflexivos pode nos ajudar a observar também a produção de índices ao longo da narração, complementando a leitura do conjunto das entrevistas ${ }^{4}$. Falamos, de um lado, de idosos denominados griots ${ }^{5}$ em suas comunidades e na relação com agentes universitários. De outro, referimos ativistas adultos do Hip Hop, forma de expressão artística que tem versado sobre condições e percursos de vida em periferias urbanas. Em ambos os casos, temos "artes de dizer" (CERTEAU, 2011) que costumam ser legitimadas pela audiência em localidades periféricas. Vejamos dois exemplos:

Na roda dos expostos... ficavam expostos ali e quase que eu fiquei ali também,
porque eu nasci mulher e o meu pai queria homem, né. Mas aí, eu sei que conversa
vai, conversa vem, se entenderam pai e mãe lá, e me aceitaram, vim pra casa.
Meus pais se encontraram na Redenção, num domingo de passeio, namoraram e
foi o primeiro e único namorado da minha mãe, se eu me lembro. Fizeram um
casamento religioso muito bonito, cheio de pompa, porque ela vivia no colégio das
freiras e as freiras que fizeram o casamento dela na Igreja Nossa Senhora da

\footnotetext{
${ }^{4} \mathrm{~A}$ inter-relação entre os depoimentos de griots e rappers foi concebida no curso da interpretação das transcrições, quando constatamos vários elementos em comum nas experiências narradas, ainda que as habilidades para narrar diferissem. Tomando, então, a audiências às falas daqueles como potencial signo de identificação, fazemos o exercício analítico complementar das "artes de dizer" para compreensão dos processos de individuação.

$5 \mathrm{Em}$ que pese a indefinição relativa à origem do nome e a diversidade de papéis e condições de reconhecimento social possíveis para o griots na África Ocidental (cantores, conselheiros políticos, artesãos, etc.), conforme assinala Hale (1997), no curso de nossas interlocuções, os griots eram citados genericamente como representantes da memória étnica negra e/ou de saberes da experiência nos territórios que habitavam.
} 
Conceição, ali na [avenida] Independência né... foi muito, pelas fotos assim, pelo relato.

[...] Só que elas tinham, as freiras tinham que pedir permissão pro arcebispo de Porto Alegre pra elas poderem emprestar ou dar o nome delas né pra gente, pros filhos das abrigadas. Então, o meu nome foi uma resistência muito grande, porque já tinha uma outra Maria Clara que a Maria Clara [freira] já tinha dado o nome dela, né. Já tinha sido liberado pra essa outra menina se chamá Maria Clara. Só que a minha mãe ficou, lutou, lutou, lutou. Eu fiquei uns dois meses sem nome e sem registro em busca da defesa do meu nome. Aí, conseguiu! A minha mãe conseguiu na Cúria Metropolitana a licença de me batizar como Maria Clara. (Ativista comunitária, 69 anos - abril/2015)

Esse excerto do depoimento assinala situações de superação de uma condição adversa, indiciando uma fabulação identitária. Foi a forma encontrada pela interlocutora para abrir a narrativa biográfica e, de certa forma, foi o preâmbulo na entrevista para uma narração repleta de casos em que os infortúnios eram enfrentados com determinação e astúcia. Em meio a isso, a autora dispunha signos de distinção, como o brio e a rede de contatos atribuídos à mãe nesse trecho, ou a proximidade a representantes políticos em outros momentos.

Então, eu tava na escola. Era uma escola pública, lá no morro que eu morava. Mas eu não gostava de tá na escola. Eu era guri e, bah, gostava de minha professora. $E$ aí tinha meus coleguinhas e minha professora tratava eles tri bem. E eu queria também, né. Aí, um dia eu vi que um deles deu um presente pra professora. Aí eu pensei: "de repente é isso. Vou dá um presente também". Mas não tinha como, né. Família grande, não tinha condições. E aí, um dia, minha mãe chega em casa com umas frutas que a patroa dela tinha dado. Fui vê e bah, tinha umas maçãs lindas, assim dessa que eu nunca tinha visto, né, brilhosa assim. Aí eu: "não, mas não vou comê! Eu vô dá pra minha professora". Era a minha maçã, não tinha outra, mas... "vô dá pra minha professora!" [falando com ênfase].

Aí, cheguei na escola no outro dia, ansioso, esperando a hora de entregar a maçã pra ela. Aí, deu o sinal, todo mundo saindo, e eu fui até a mesa dela, peguei a maçã e disse: "óh professora, pra senhora!" [encenando com a mão estendida e fisionomia de expectativa]. E ela disse: "ah, tá, deixa aí. Obrigado!".

Bom, saí da sala; fiquei me perguntando se ela tinha gostado. E aí, pah: "vou apagar o quadro pra professora!". Voltei lá correndo e, quando coloquei a cara na porta, eu vi a professora, ela tava colocando minha maçã no lixo.

Foi aí que eu comecei a fica com a turma do fundo. Foi aí que eu comecei a dá porrada.

[...] Trabalhei no tráfico de drogas e foi na arte que eu encontrei uma alternativa. (Mano, rapper, 37 anos - out/2016)

A narrativa apresentada a nós, pesquisadores universitários do campo da educação, e do qual destacamos o trecho acima, tem presente um jogo de signos a evocar ícones comuns ao imaginário sobre a relação professor-aluno e a ingenuidade atribuída à criança, para reverter em uma história de racismo. Em sua locução conta também seu posterior envolvimento com o tráfico de drogas e desenha uma ligação entre as violências sofridas na infância e sua incursão pelo mercado ilícito. Trabalhou para o tráfico, mas teria sido a arte que o possibilitara uma alternativa e conhecimento.

Os dois exemplos selecionados destacam adversidades e injustiças e celebram a agência individual no tratamento destas; apoiam-se em signos que realçam as dificuldades 
enfrentadas, as consequências ou as virtudes dos protagonistas, incluindo-se aí as pertenças e as referências simbólicas que suportam a existência individual e coletiva. Nisso, as narrativas indiciam de certa forma as posições ambivalentes que mencionamos antes.

Eis que, tomando a breve análise da configuração dos itinerários em associação ao agenciamento narrativo exemplificado, aqui, gostaríamos de remeter nossa intepretação às contribuições de Martuccelli (2010). Consideramos a hipótese de que, especificamente para os contextos de periferia, cabe uma aproximação à tese da configuração de um "hiper-ator" nos processos de individuação, aventando, aqui, a importância da manutenção do laço social e a interposição cotidiana de um poder indicativo.

As narrativas que abordamos são delineadas desde os feitos protagonizados e as adversidades superadas, configurando itinerários permeados de intermitências e insuficiências. Pode-se depreender certo "fazer por si" no que é contado, posto sistematicamente em iniciativas agênticas a compensar os recursos que se "indicam" mas não se estabelecem. E vale ressalvar, as narrações não se apresentavam ainda assim como uma exposição de realizações resultantes de êxitos individualizados. Narravam individualidades que valoravam os laços de reciprocidade que suportavam sua existência, destacadamente em relações próximas, para fazer frente a um mundo que não os "continha".

\subsection{Trabalho e território: nuances na individuação}

Os excertos tratados acima possibilitam, de outra parte, que problematizemos uma diferenciação importante: a reflexividade do segundo excerto indicia uma crítica do autor da narrativa em relação à instituição escolar, que entendemos ser também o marco narrativo de seu sentimento de desfiliação. Os itinerários biográficos dos idosos representam a necessidade de agenciamentos em meio à precariedade, mas desde buscas por filiação; o rapper, bem como outros adultos e jovens que entrevistamos, posicionam sua individualidade frente às estruturas e indicam certo "mal estar" da incompreensão e/ou não reconhecimento.

Já há décadas, análises sociológicas assinalam a transformação das relações sociais contida na modernidade tardia, incluindo dinâmicas de restruturação da organização produtiva e das regulações no mundo do trabalho, incremento na apropriação tecnológica e conectividade cotidiana, diversificação das bases de referência para socialização, dentre outros, promovendo processos de destradicionalização reflexiva e individualização frente aos vínculos gestados nas outrora sociedades industriais (BECK, 2012).

Nesse entretanto, no que tange às localidades de periferia urbana, há alguns fenômenos que podemos elencar para dar contorno a uma leitura contextualizada. E, aqui, um contraste etário também pode ser profícuo. Na vivência do mundo do trabalho, uma importante prova-social para o cenário em foco, ainda que as relações fossem constituídas sob condições precárias para os idosos, incluindo migrações e intermitências, o referente era 
a busca e manutenção de laços duradouros e estáveis, mesmo na informalidade. Ao passo que, com os jovens, as narrativas sobre as inserções laborais indiciam intensificação e instabilidade, como já indicava Corrochano (2016). De tal forma, entendemos interpor-se as consequências da flexibilização dos vínculos laborais e a fragilização dos parâmetros de proteção social a eles atrelados, como assinalava Guimarães (2011).

Meu pai era muito amigo do patrão dele. Aí, ele conseguiu um emprego pra mim no Rio de Janeiro. Trabalhava num apartamento. Lembro quando vi o Juscelino [presidente] passando de carro na rua.

[...]É, meu pai dizia pra gente: "pobre tem que procurá uma árvore bem grande, de dê bastante sombra". (Nila, empregada doméstica, 76 anos - set/2015)

Eu trabalhei cinco mês, fiquei super triste quando eles me mandaram embora. Meu primeiro serviço, né. Depois, eu fiquei dois mês no 'Bela Gula', que foi no tempo que meu irmão tava vivo, e depois ele faleceu e eu acabei saindo [...] No último trabalho, era fastfood também. Eu gosto de cozinha, mas eu tava trabalhando por dois e aí decidi sair. Fiquei uns seis meses, aí. (Guilherme, MC Funk, 25 anos - maio/2012)

De outra parte, Feltran (2014) argumenta ter havido uma inflexão nas políticas sociais nas últimas décadas, de modo que a figura do "trabalhador" seria tensionada como balizador do horizonte normativo e na definição dos problemas sociais. Ainda que este permaneça crucial na organização de direitos, o conflito social teria se deslocado para a tematização da violência urbana, das drogas e da marginalidade. Neste ínterim, a polarização moral entre "trabalhador" e "marginal" ganha maior expressão, de forma que a organização das iniciativas de governo se situariam entre a proteção e o controle, a ponderar a situação de vulnerabilidade desde suporto potencial de risco e as possibilidades de (re)integração atinentes. Seriam as periferias as principais destinatárias de tais políticas.

Tais territórios têm sido palco do domínio de grupos vinculados ao crime organizado, particularmente ao tráfico de drogas, sendo que os conflitos entre estes e com a polícia dispõem situações de medo e desconfiança. Dado que a ação dos aparatos policiais é episódica e, muitas vezes, tão truculenta quanto a de agentes do tráfico, os indivíduos se veem sob a necessidade de encontrar alternativas que suportem o cotidiano. Então, os moradores se voltam às relações de reciprocidade, mesmo que com os vizinhos que administram as "bocas de fumo" (PIMENTA, 2015).

Tinha tráfico, a Cruzeiro sempre foi de tê tráfico, mas era um tráfico diferente. Eu lembro que a gente, de curioso, via os malandros na esquina e chegava para ver o que eles tavam fazendo; a gente chegava e tomava um tapão no ouvido. "Sai daqui, piá, te arranca do meio". E iam na casa, às vezes quando tu ficava rodeando demais, eles te pegavam no braço e chegavam na tua casa, "Óh tia, a gente tá fazendo coisa errada, tira esse guri do meio". Os caras tinham consciência, cara.

Hoje tu chega... um piá de 11 anos. Eles dão uma arma na mão deles: "toma aqui e vai naquela esquina pra mim. Quantos mortes de adolescentes nós vimos. Tu nem sabe quem são os cara. (Lula, ativista cultural, 35 anos - out/2017) 
Segundo observamos, entretanto, a dinâmica competitiva atual no mercado de tráfico intensifica a fragilização de parte dos vínculos nos territórios. De um lado, a virulência dos atos violentos e, de outro, a alternância dos sujeitos que controlam as regiões em disputa fazem com que a interação e o laço sejam obliterados. Seja pelas situações de morte, seja pelo arranjo dos embates entre grupos que percorrem diferentes localidades no município, as pessoas que controlam localmente a venda de drogas nem sempre são conhecidas. Então, o risco não é experienciado só em função de ações belígeras e sua amplificação discursiva. $A$ questão é também a ruptura dos laços de reciprocidade e reconhecimento, e a fragilização de um artifício habitual na conquista de segurança cotidiana. Os vínculos ora mencionados por Velho (2000) estariam a sofrer uma inflexão.

Nesse cenário de debilitação de laços, é possível aventar que a experiência de medo e fragilidade redimensiona as polarizações morais. Caso se opere com os signos 'trabalhadores' e 'bandidos' (ZALUAR, 1994; FELTRAN, 2014), a delimitação variável destes no cotidiano, faz com que as categorias sejam acompanhadas de narrativas nas quais os juízos indicam posições limítrofes na condução das escolhas individuais, como 'confiável-não confiável', 'seguro-inseguro', 'protegido-desprotegido', 'perdido-recuperado'. As periferias urbanas viveriam, assim, uma versão cruciante da sociedade de risco, no manejo das contingências e das probabilidades de segurança (BECK, 2015) .

Consideramos, dessa forma, que, junto de uma relação tensionada com programas institucionais, o cenário acena para um aguçamento do "trabalho dos indivíduos" na produção dos laços sociais. Vejamos exemplos para tal hipótese. Em muitos casos, observávamos que a obtenção de trabalho por jovens se dava por indicações oriundas das redes familiares, ainda que para atividades informais e temporárias. Entendemos, ademais, que a valoração enunciativa de redes e dinâmicas familiares (como comentado antes), com destaque ao papel protetivo da mãe (na maioria dos casos, aquela que permanece junto à prole), projeta-se em tal quadro de incertezas. O uso da palavra "família" para nominar, aliás, diferentes agrupamentos conviviais (das relações de amizade às iniciativas do tráfico) parecem nos remeter à necessidade de sinalizar a relevância da lealdade na manutenção de vínculos em terreno instável.

No caso aqui é o "FreeStyle". No grafite, tem cinco tipo de grafite, um deles se chama freestyle; quer dizer "estilo livre", né. É uma coisa, tipo: "Ah, livre, eu sou livre". O "Hip Hop" foi a primeira tatuagem que eu fiz. Eu tava começando. Aqui, as iniciais de cada membro da minha crew. O "RC" é Restinga Crew. Aqui, minha mãe, eu e minha irmã, eterno! O "S" de sabedoria; muito importante, o "S" também do nome da minha mãe, que é Sandra e, aí, é um "S" em estilo grafite também. A

\footnotetext{
${ }^{6}$ Nas palavras do autor, "o risco constitui um modelo de percepção e de pensamento da dinâmica mobilizadora de uma sociedade, confrontada com a abertura, as inseguranças e os bloqueios de um futuro produzido por ela própria e não determinado pela religião, pela tradição ou pelo poder superior da natureza" (BECK, 2015, p. 21).
} 
"caveira" e a frase "Bboy or die", que é "bboy até a morte". Aqui, são duas tampinhas de spray, que querem simbolizar um o grafite e o outro a dança. Aqui na orelha tem o "desenho do coringa", mas é uma coisa minha, porque eu sou muito fã do coringa, eu acho muito interessante a história, não pelo que ele faz com a humanidade, mas pelo jeito que ele lida com diversas situações. Uma coisa que o Batman não consegue tirar dele é o sorriso, mesmo que ele esteja na pior, nunca consegue tirar o sorriso dele. Na barriga, tenho Restinga Crew tatuado: Restinga Crew é família, tinha que representar de alguma forma, né?! Então, todas as minhas tatuagens têm significado; nunca faço tatuagem sem significado, não consigo! (Cko, bboy, 26 anos - out/2015)

Outro exemplo e circunstância nos remete à apropriação da prática educativa. O espaço institucional com o qual pode ter havido uma relação tensa se converte em um locus onde se projeta segurança. Seja na forma de um ambiente físico delimitado, com controle dos tempos vividos, seja pela expectativa de socialização moral. Então, para além da convencional articulação com o mundo do trabalho, em geral inscrita em certo porvir, a habitação de ambiências educativas é significada no presente desde as ambivalências do risco que mencionamos acima.

Então, acho que o basquete, a cultura, independente de qualquer coisa, eu acho que salva. A música salva, o basquete salva, o futebol salva, né. [...] A característica, na minha opinião, assim... é sobrevivência [...] Então, de alguma forma eu tô lá nas minhas oficinas, também, pra ajudá eles de alguma forma boa. (Deco, oficineiro, 38 anos - maio/2016)

\section{Considerações finais}

Iniciamos nossa abordagem propondo a análise de processos de individuação em localidades de periferia. Procuramos fazer, então, que a produção de narrativas se prestasse à configuração de experiências, com vistas a um exercício analítico dos acontecimentos narrados e também da forma como enunciavam itinerários.

Nesse sentido, a interpretação dos percursos narrados indicaram a necessidade aguda de atuação dos indivíduos na construção das condições de subsistência. O exame de aspectos da narração de nossos interlocutores propiciaram complementos, ademais, para que considerássemos a configuração de uma individuação agêntica nas localidades de nossos diálogos, remetendo-nos à figura do "hiper-ator" sugerida por Martuccelli (2010). Mais além, seguindo este mesmo autor, pudemos discutir nuances expostas por um contraste etário, a sinalizar para a tendência à intensificação do "trabalho dos indivíduos" na produção de laços sociais.

Isso dado em um cenário de flexibilização de vínculos de trabalho e fragilização de laços de reciprocidade no território, que lembram as contribuições de Beck (2015) sobre a "sociedade de risco", que as periferias parecem viver em sua versão lancinante, por conta das intermitências nas ocupações laborais, onde já se vivia precariedade pecuniária, e das disputas violentas entre agentes do tráfico de drogas e da polícia, a interpor intensa 
instabilidade cotidiana. Se, para as relações capitalistas contemporâneas, a realidade de conflito e violência em localidades socialmente vulnerabilizadas é notória, é preciso ir ao que sentem e anseiam os indivíduos de tais contextos para compreender suas tomadas de posição.

\section{Referências}

ARAUJO, Katia, MARTUCCELLI, Danilo. La individuación y el trabajo de los individuos. Educação e pesquisa, v. 36, p. 77-91, 2010.

BARTHES, Roland. Introdução à análise estrutural da narrativa. In: BARTHES, Roland. et al. Análise estrutural da narrativa. Rio de Janeiro: Vozes, 2011, p. 19-62.

BECK, Ulrich. A reinvenção da política. In: GIDDENS, Anthony, LASH, Scott, BECK, Ulrich. Modernização reflexiva. São Paulo: UNESP, 2012, p. 11-88.

BECK, Ulrich. A sociedade de risco mundial: em busca da segurança perdida. Lisboa: Edições 70, 2015.

CERQUEIRA, Daniel et al. Atlas da violência 2018. Rio de Janeiro: IPEA, 2018.

CERTEAU, Michel De. A invenção do cotidiano - 1. Artes de fazer. Petrópolis: Vozes, 2011. CORROCHANO, Maria C. Trabalho e condição juvenil: permanências, mudanças, desafios. In: NOVAES, Regina et al. (orgs.). Agenda juventude Brasil: leituras sobre uma década de mudanças. Rio de Janeiro: UNIRIO, 2016, p. 155-174.

DELORY-MOMBERGER, Christine. Abordagens metodológicas na pesquisa biográfica. RBE, 17(51), p. 523-536, 2012.

FELTRAN, Gabriel. O valor dos pobres: a aposta no dinheiro como mediação para o conflito social contemporâneo. CRH, 27(72), p. 495-512, 2014.

GEORGES, Isabel. Práticas e dispositivos: escalas, territórios e atores. Contemporânea, 06(01), p. 51-73, 2016.

GUIMARÃES, Iracema. Periferias e territórios sob efeitos conjugados da precarização: algumas tendências. Cadernos CRH, 24, p. 89-104, 2011.

Hale, Thomas. From the griot of roots to the roots of griot: a new look at the origins of a controversial African term for bard. Oral Tradition, 12(2), p. 249-278, 1997.

JOVCHELOVITCH, Sandra. Entrevista narrativa. In: BAUER, Martin. Pesquisa qualitativa com texto, imagem e som. Petrópolis: Vozes, 2002, p. 90-113.

MARTUCCELLI, Danilo. Cambio de rumbo: la sociedad a escala del individuo. Santiago: LOM, 2007.

MARTUCCELLI, Danilo. ¿Existen individuos en el Sur? Santiago: LOM Ediciones, 2010.

MARTUCCELLI, Danilo. La individuación como macrosociología de la sociedad singularista. Persona y Sociedad, XXIV(03), p. 09-29, 2010b. 
MARTUCCELLI, Danilo. Soportes. In: MARTUCCELLI, Danilo. Gramáticas del individuo. Buenos Aires: Losada, 2008, p. 37-106.

MOURA, Rosa. O que é periferia urbana. São Paulo: Brasiliense, 1996.

NUNES, Marion. Série Memórias dos bairros. Porto Alegre: PMPA, 2006.

OBSERVAPOA. Porto Alegre em análise. Séries históricas - Censos Populacionais

IBGE. Disponível em: <http://portoalegreemanalise.procempa.com.br>. Acessado em: mar/2017.

PIMENTA, Melissa. Relações de poder e controle social em áreas de grande exposição à violência. Civitas, 15(01), p. 84-104, 2015.

PINHEIRO, Leandro R. Individuação em periferias urbanas: aportes desde a produção de narrativas. Atas do $8^{\circ}$ Congresso Ibero Americano de Investigação Qualitativa - Ciências Sociais, Lisboa/Portugal, julho/2019. Disponível em: https://proceedings.ciaiq.org/index.php/ CIAIQ2019/article/view/1992.

ROCHA, Ana. L. C., ECKERT, Cornélia. Etnografia: saberes e práticas. In: PINTO, Céli et al. (orgs.). Ciências Humanas: pesquisa e método. Porto Alegre: Editora UFRGS, 2008, p. 0924.

ROCHA, Ana. L, C; ECKERT, Cornélia. Memória, história e as histórias do mundo. Anais do 23ํㅡㄹ Encontro Anual da ANPOCS, Caxambú/MG, 1999.

SANCHIS, Pierre. Cultura brasileira e religião... passado e atualidade. Cadernos CERU, 19(02), p. 71-92, 2008.

SCHÜTZE, Fritz. Pesquisa biográfica e entrevista narrativa. In: WELLER, Wivian. (org.). Metodologias da pesquisa qualitativa em educação: teoria e prática. Vozes: Petrópolis, 2010, p. 210-222.

SOUZA, Jessé. A ralé brasileira: como é e como vive. Belo Horizonte: Editora UFMG, 2009. VELHO, Gilberto. Individualismo, anonimato e violência na metrópole. Horizontes Antropológicos, ano 06, n. 13, p. 15-29, jun/2000.

ZALUAR, Alba. Crime, justiça e moral: a versão das classes populares. In: ZALUAR, Alba. Condomínio do diabo. Rio de Janeiro: UFRJ, 1994, p. 72-81. 